AperTO - Archivio Istituzionale Open Access dell'Università di Torino

\title{
A STUDY ON REVERSIBILITY OF BEVA®371 IN THE LINING OF PAINTINGS
}

\section{This is the author's manuscript}

Original Citation:

Availability:

This version is available http://hdl.handle.net/2318/1506005

since 2015-07-22T14:00:54Z

Published version:

DOI:10.1016/j.culher.2014.09.001

Terms of use:

Open Access

Anyone can freely access the full text of works made available as "Open Access". Works made available under a Creative Commons license can be used according to the terms and conditions of said license. Use of all other works requires consent of the right holder (author or publisher) if not exempted from copyright protection by the applicable law. 
Elsevier Editorial System(tm) for Journal of Cultural Heritage

Manuscript Draft

Manuscript Number: CULHER-D-13-00293R1

Title: A STUDY ON REVERSIBILITY OF BEVA®371 IN THE LINING OF PAINTINGS

Article Type: Original Article

Keywords: BEVA®371, lining operation, reversibility, painting conservation

Corresponding Author: Prof. Oscar Chiantore, Professor

Corresponding Author's Institution: University of Torino

First Author: Lisa Bianco

Order of Authors: Lisa Bianco; Massimiliano Avalle; Alessandro Scattina; Paola Croveri; Cesare Pagliero; O. Chiantore, Professor

Abstract: The adhesive properties of BEVA®371 used in the lining of paintings and the reversibility and invasiveness of the operation as a function of the different application conditions has been investigated in this work. Peel and lap shear mechanical tests on specific samples were then done in order to study the adhesion effectiveness. After the tests, cross-sections of samples were observed under optical microscope to examine the adhesive distribution, moreover the samples were examined with SEM analysis to evaluate the adhesive invasiveness. Also a series of removal tests of lining fabrics from an original painting were done in order to establish the method allowing the highest degree of reversibility. The influence of artificial ageing was evaluated on a series of samples subjected to thermal-hygrometric stress for some months. Changes in the elastic and adhesive properties were observed, but all together the study indicates that from the mechanical point of view BEVA®371 is a quite stable material for lining operations made with properly controlled application methods.

Response to Reviewers: See file attached: Detailed response to reviewers 
To the Editorial Office

Journal of Cultural Heritage

25 July 20

Dear Editor,

I am submitting, on behalf of all the Authors, the revised version of our contribution "A study on reversibility of BEVA $® 371$ in the lining of paintings", which has been previously assigned the Ms. Ref. N ${ }^{\circ}$ CULHER-D-13-00293 under a slightly different title.

The text of the manuscript has been substantially rewritten and the Figures and captions improved, in accordance with the suggestions and comments received from all the reviewers and from the Editor (Jan 10, 2014). A full account of the changes we have made is in the attached file "Detailed response to reviewers".

The comments and suggestions we have received have been very useful to us for improving the discussion of the results and for getting rid of some misunderstanding. The lining of paintings and the adhesives behaviour is a topic of major interest in the conservation area, and the debate on applications is never closed. We believe the work we are submitting here can contribute to advancements in the field, and we therefore hope it will be accepted for publication in Journal of Cultural Heritage.

With kindest regards,

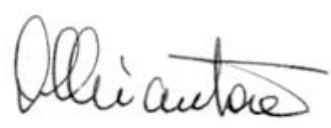

Oscar Chiantore 


\title{
A STUDY ON REVERSIBILITY OF BEVA ${ }^{\circledR 371 ~ I N ~}$ THE LINING OF PAINTINGS
}

Lisa Bianco ${ }^{\mathrm{a}}$, Massimiliano Avalle $^{\mathrm{b}}$, Alessandro Scattina ${ }^{\mathrm{b}}$, Paola Croveri ${ }^{\mathrm{a}, \mathrm{c}}$, Cesare Pagliero $^{\mathrm{d}}$, Oscar Chiantore ${ }^{\mathrm{c}^{*}}$

${ }^{a}$ Centro Conservazione e Restauro La Venaria Reale, via XX Settembre 18, 10073 Venaria Reale (Torino), Italy.

${ }^{\mathrm{b}}$ Politecnico di Torino, Dipartimento di Ingegneria Meccanica e Aerospaziale, Corso Duca degli Abruzzi, 24 - 10129 Torino Italy.

${ }^{c}$ Università degli Studi di Torino, Dipartimento di Chimica, Via P. Giuria, 7 - 10125 Torino Italy.

${ }^{\mathrm{d}}$ Conservator, free lance, Via Torre dei Cavalli, 22 Savigliano (CN).

* Corresponding author. Tel.: +39 0116707558; fax: +39 0116707855

E-mail addresses:

lisabianco_LB@libero.it (Lisa Bianco)

massimiliano.avalle@polito.it (Massimiliano Avalle)

oscar.chiantore@unito.it (Oscar Chiantore)

paola.croveri@unito.it (Paola Croveri)

alessandro.scattina@polito.it (Alessandro Scattina)

cesare.pagliero@alice.it (Cesare Pagliero)

\begin{abstract}
The adhesive properties of BEVA®371 used in the lining of paintings and the reversibility and invasiveness of the operation as a function of the different application conditions has been investigated in this work. Peel and lap shear mechanical tests on specific samples were then done in order to study the adhesion effectiveness. After the tests, cross-sections of samples were observed under optical microscope to examine the adhesive distribution, moreover the samples were examined with SEM analysis to evaluate the adhesive invasiveness. Also a series of removal tests of lining fabrics from
\end{abstract}


an original painting were done in order to establish the method allowing the highest degree of reversibility. The influence of artificial ageing was evaluated on a series of samples subjected to thermal-hygrometric stress for some months. Changes in the elastic and adhesive properties were observed, but all together the study indicates that from the mechanical point of view BEVA®371 is a quite stable material for lining operations made with properly controlled application methods.

KEY WORDS: BEVA®371, lining operation, reversibility, painting conservation

\section{Introduction}

BEVA®371 was introduced at the Greenwich conference in 1974 [1] as the first product specifically developed for restoration of paintings. Thanks to Gustav Berger's research regarding lining and paintings consolidation with synthetic materials [2], this adhesive has been widely adopted in the conservation field. BEVA®371 has the main important characteristics sought by restorers: high adhesive capacity and physico-chemical adequate properties even after accelerated or natural ageing $[3,4]$. At the same time, it is able to ensure protection against thermo-hygrometric variations and structural support to paintings, as demonstrated in different works [5-7].

The BEVA®371's properties have been investigated by studying the effects of different variables in canvas treatments: application modes, temperature $[8,9]$, pressure, thickness of adhesive layer [10,11], adhesive thinning, lining fabrics typology [12], and presizing $[13,14]$. The bonding between painting canvas and lining materials is influenced by these variables, which can lead to different results in terms of adhesion, durability and reversibility.

The claimed advantages of BEVA®371 do not always find confirmation in the practice by restorers, as documented some years ago in a worldwide survey of lining techniques [15] and reiterated in a survey of about 60 Italian restorers we have recently done. In 
practice, application is mostly driven by subjective evaluation criteria, by the restorer's experience and personal perception and not by a correct understanding of properties and treatment conditions of the adhesive [16]. As a result, BEVA®371's improper use without knowledge of the consequences generated worries regarding future operations on the lined paintings.

From the chemical composition point of view, the original formulation recipe of BEVA®371 consists in a mixture of several substances including two Ethylene-Vinyl Acetate copolymers differing in monomer compositions and molecular weights, a low molecular weight polycyclohexanone resin, a paraffin wax and phtalate ester of hydroabietyl alcohol [17]. The components are dissolved in a mixture of solvents including octanes, toluene and naphtha petroleum, having high retention and partly toxic. For this reason many strong criticisms were raised against this product and its environmental pollution effects, and against the risks of alteration of the original art materials, either in the support or in the paintings. The possible side effects are still not known today. The goal of decreasing the amount of contaminants in works of art is always desirable, and a research project concerning the substitution of some chemical constituents of BEVA®371 and the simplification of its formulation was recently started and is under development [18].

From the point of view of the interaction with the constituent materials, to ensure the lowest invasiveness of lining operation the adhesive rupture should take place between the adhesive and the original support [19], and it was established that a good lining should have peel strength values between 300 and $400 \mathrm{~N} / \mathrm{m}$ [20, 21]: above these values the de-lining can be dangerous and the separation between the two adherends is difficult. The goal of this work is to evaluate the reversibility degree of the restoration operations accomplished with BEVA®371, the impact of the lining on the paintings and the 
possibility of a limitation in its use. A series of peeling, lap shear and de-lining tests were performed and the migration and penetration degree between painting canvas and lining canvas was investigated. The methods employed and the results obtained are here discussed.

\section{Materials and methods}

\subsection{Operating use and application methods $B E V A \circledast 371$}

Our survey among the professional restorers operating in Italy, who declared they regularly use BEVA®371, was of help in planning the laboratory samples preparation. In lining operations most of the restorers apply the adhesive on the auxiliary support only $(60 \%)$, while fewer do on the original painting (10\%), or on both supports $(30 \%)$. As to the application method, BEVA®371 is applied mainly by spraying (47\%) and then with spatula (24\%), roll (22\%) and brush (9\%), diluting it with White Spirit or other solvents, like cyclohexane, rectified gasoline and toluene, or thinner 372 which was expressly formulated by CTS (Italy) for Gustav Berger’s BEVA®371 original formula. Polyester supports are more used (66\%) than linen ones (34\%).

The lining operation is made using the iron coupled with vacuum (45\%), and the low pressure hot-table (45\%), but also a vacuum bag system and heat supplied with Melinex bags containing hot water $(10 \%)$. The plasticization of BEVA®371 is produced in a temperature range between 55 and $80^{\circ} \mathrm{C}$.

Starting from this information, specimens were prepared with the following different protocols:

- three different application modes of BEVA®371: by spraying, with spatula, from film;

- two types of fabrics usually employed by conservators: linen and polyester;

- re-plasticization temperatures: $62^{\circ} \mathrm{C}, 68^{\circ} \mathrm{C}$ and $75^{\circ} \mathrm{C}$; 
- in the case of applications with spatula or spray two different lining procedures have been applied to the laboratory specimens. In one series the adhesive was applied onto the auxiliary fabric and the lining performed at the selected temperature. In a second series the adhesive was heated on the auxiliary fabric before lining with low pressure and temperature.

\subsection{Sample preparation}

The mechanical tests were performed on laboratory specimens prepared with materials reasonably representative of the canvas-lining coupling situations, having at the same time the weaving regularity and structure homogeneity necessary for the comparison of results. For such reasons the choice for model canvas was a commercial linen $(10 \times 10$ yarns $/ \mathrm{cm}$ ) with acrylic priming, while for the lining support a $15 \times 15$ yarns $/ \mathrm{cm}$ linen canvas and a $15 \times 16$ yarns/cm polyester one, both typically used as lining materials, were selected. Strips for peel and lap shear tests were cut in the weft direction, and lining was done making weft and warp coincide. Prior application, the linen fabrics were washed. The BEVA®371 used is the Gustav Berger Original Formula, distributed by C.T.S. S.r.l., Italy. It should be mentioned that in 2010 the BEVA®371 composition was slightly modified because the original ketone resin was commercially discontinued, and a new formulation was introduced with an alternative resin. It was claimed that the mechanical performance of the new formulation is comparable with the original formulation, however the new BEVA®371 is slightly yellow instead of colourless [22].

Both the paste ( $40 \%$ of solute in $60 \%$ of solvent) and the film formulation, with a thickness of $62 \mu \mathrm{m}$, were used. The adhesive was applied on the auxiliary support using the three different methods illustrated before, on areas $90 \mathrm{~cm}$ wide by $16 \mathrm{~cm}$ high. The paste was pre-heated at $40-50{ }^{\circ} \mathrm{C}$ before the application with spatulas at room temperature. The same amount of adhesive was applied ( $c a .12 \mathrm{~g}$, measured by weighting 
the canvas specimens) in order to compare the different samples. Specimens with $10 \mathrm{~cm}$ by $16 \mathrm{~cm}$ dimensions were subsequently obtained by cutting.

The painting canvas and the front border of lining canvas were bonded to a stiff wood support with a polyurethane adhesive (Figure 1) in order to ensure the correct clamping of samples in the testing machine.

In the spray application the BEVA®371 was diluted 1:1 in cyclohexane. This solvent was chosen for its low toxicity and evaporation rate, and spraying was done at $c a .40-50{ }^{\circ} \mathrm{C}$. Thanks to the air compressed gun it promotes the lay down of adhesive with creation of a typical flocked texture. Lining of samples was made on a hot table with low pressure (ca. $160 \mathrm{hPa}$ ) using the different re-plasticization temperatures previously indicated. During the activation phase the temperature on the samples surface was checked with an infrared thermometer.

For the spatula and spray applications, the lining was done after 4 days in order to allow the solvents evaporation. To obtain an adhesive distribution more similar to the case of BEVA®371 film, two different application procedures were employed as previously described and the effects on bond strength and reversibility degree were investigated. The samples examined in this work and their nomenclature are summarized in Table 1.

\subsection{Samples ageing}

A series of samples was subjected to ageing by exposure to harsh external environment for 5 months under temperature excursions ranging between 37 and $-7{ }^{\circ} \mathrm{C}$, and relative humidity from 10 to $90 \%$. Similar conditions are exceedingly severe and not normally applied to paintings.

\subsection{Peel tests and lap shear tests}

Peel tests [23] between painting canvas and lining canvas were made. The purpose of this test is to separate two surfaces joined by adhesive applying force to one of the surfaces in 
order to evaluate the adhesive strength of the different lining systems. Usually the angle of the applied force is $90^{\circ}$, in this case the angle between the two canvases was set to $180^{\circ}$ in order to better simulate the de-lining operation (Figure 1). The tests were carried out with an Instron 8801 testing machine, using a $10 \mathrm{kN}$ load cell. The test speed was 0.5 $\mathrm{mm} / \mathrm{s}$ for a stroke of $100 \mathrm{~mm}$. For each sample type three repetitions were done. With the obtained measurements, the peel strength, defined as the ratio between the average peak force and the width of the specimen, was evaluated. The average peak force was estimated in the steady state part of the force-displacement curve (between 15 and 100 $\mathrm{mm}$ stroke, Figure 2).

Also lap shear tests [24] were performed on some samples both before and after the ageing. In the lap shear test two plates are bonded together with adhesive and cured. The plates are positioned in the grips of a testing machine and pulled until failure of the adhesive (Figure 1). The purpose of this test is to evaluate the tearing strength. For this type of test, a $100 \mathrm{kN}$ load cell was used, for a stroke of $20 \mathrm{~mm}$.

\subsection{Visualization and analysis of $B E V A \circledast 371$ penetration and migration degree between painting canvas and lining fabrics}

A contrast UV fluorescent marker (hydrophilic dye: Ponceau 4R) was used to discriminate BEVA®371 adhesive at the interface between canvas painting and lining fabric, and to investigate the migration and penetration entity of the material inside the glued system. The dye was applied on the cross sections obtained from the samples, which were examined with an optical microscope.

\subsection{Removal test of lining canvas}

Different removal methods were tested in order to evaluate the process of debonding which relates to the cohesive or adhesive failure of the composite formed by the lining fabric, the adhesive and the painting canvas. The tests were performed on samples lined 
with BEVA®371 film at $68{ }^{\circ} \mathrm{C}$ on polyester fabric (P_F68) for having uniform characteristics of the support and the adhesive. Both the effect of lining and the method for adhesive removal from the original support were verified. For the lining removal tests the canvas specimens have been glued from the front side on a fixed wooden support. Three different removal systems were adopted:

- Mechanical removal done manually by pulling the strip of the lining tissue in tangential direction, with the force required for the gradual detachment of the two layers.

- Solvent removal, done by rubbing the lining support with a cyclohexane impregnated cotton swab and pulling to detach from the canvas.

- Hot removal, performed in two different ways. An hot air gun was located close to the surface in order to have air flow, at $36^{\circ} \mathrm{C}$, touching the surface tangentially. In the other way, the lining strip was heated at ca. $50^{\circ} \mathrm{C}$ with an IR lamp before pulling away.

Lining removal was evaluated by observations with a stereomicroscope Olympus SZ-X10 in reflected light of the two supports after their separation; the presence of the adhesive on either substrate could be visually evaluated.

\section{Results and discussion}

\subsection{Peel and lap shear strength}

The results of the peel tests (Table 2 and Figure 2) and lap shear tests (Table 3 and Figure 3) showed a higher adhesive strength of the samples lined with the linen support rather than the polyester, in particular if the spray applying method is used (L_ZXX series). This type of specimen showed best performance in terms of adhesive capacity and adhesive strength both in peeling (between 300 and $400 \mathrm{~N} / \mathrm{m}$ ) and in shear $\left(0.24 \mathrm{~N} / \mathrm{mm}^{2}\right)$. Peel strength optimal values $(280-400 \mathrm{~N} / \mathrm{m})$ were reached. On one side, using the spray 
application the adhesive is better distributed on the surface than with the spatula; on the other side the solvent promotes a more homogeneous mixture between the different formulation components of the paste adhesive.

BEVA®371's adhesive properties are directly proportional to re-plasticization temperature as shown in the tests on samples lined at $68{ }^{\circ} \mathrm{C}$. To verify this phenomenon related to viscosity and penetration into the texture of the fabric, a series of samples lined with BEVA®371 Film at $75{ }^{\circ} \mathrm{C}$ was also tested (Table 2). This type of adhesive film needs higher temperatures to ensure the same performance as the adhesive in paste form. Moreover, the different BEVA®371 treatments have also effects on the adhesive properties: samples lined directly have higher properties than those with intermediate replasticization.

Ageing caused relevant changes on the BEVA®371 adhesive properties. The peel strength values (as shown in Table 4 and Figure 2) in most cases are lower but in others either increased or did not change. These results are not easy to interpret and they could be tentatively attributed to effects produced by different canvas - adhesive - lining interfaces in the specimens. Considering the lap shear results (Figure 3), the maximum load is always higher for the aged specimen compared to the same type of specimen before ageing. The same behaviour is enhanced using higher re-plasticization temperature. It turns out that the ageing increases the shear strength of the adhesive.

\subsection{Evaluation of adhesive migration and penetration between two supports}

Thanks to the application of a contrast marker the adhesive distribution between painting canvas and lining fabric could be studied by observation of the cross section of samples under an optical microscope. The UV induced fluorescence indicates that the different adhesive treatment (direct lining or intermediate re-plasticization plus lining) has some influence on the migration and penetration degree in the original support, as shown in 
Figure 4 by the comparison between samples L_Z681 e L_Z682, lined with linen canvas using the two different procedures: In the sample L_Z682 (image B of Figure 4) the BEVA®371 was applied to the linen auxiliary support (fibers in section 4 of the Figure) by spraying and then heating at $68^{\circ} \mathrm{C}$ for re-plasticization before adhering to the canvas (fibers in section 2 of the Figure), and this procedure allows to obtain an apparent more efficient distribution of the adhesive.

\subsection{Evaluation of lining removal}

The de-lining test results are summarized in Figure 5 where the four microscopic images show the area of separation between the painting canvas (upper part) and the lining fabric (lower part) for the sample P_F68. Four different removal techniques were considered: dry mechanical removal (A), solvent removal with cyclohexane (B), hot removal at $36{ }^{\circ} \mathrm{C}$ with air gun (C), hot removal at $c a .50{ }^{\circ} \mathrm{C}$ with infrared heating lamp (D). The dry mechanical removal of the lining fabric from the painting canvas (image A) ensures a better degree of removal / reversibility of the adhesive from the support of the painting because it promotes a more effective separation of the adhesive and the lining fabric. Differently from solvent and hot based removal (images B, C e D) where an increased release of partially solubilized or re-plasticized BEVA®371 remains as a residue on the canvas.

The dry removal of the auxiliary fabrics has also allowed to evaluate the actual invasiveness of the lining systems tested. In Figure 6 are compared, as an example, the differences between the canvas surfaces after the removal of lining with BEVA®371 film re-plasticized on linen at $68^{\circ} \mathrm{C}$ (image A) and a corresponding sample treated at $75^{\circ} \mathrm{C}$ (image B). The adhesive properties in both cases were very good, but with replasticization at $75{ }^{\circ} \mathrm{C}$ much more adhesive was left on the canvas support (on the right of the images in Figure 6) after the lining removal. 
In Figure 7 the comparison between samples L_Z681 and L_Z682, among the best samples from the point of view of the bond strength and the adhesion system, shows that higher reversibility (L_Z682, image B) is obtained in the system where BEVA®371 has been applied with spray and intermediate re-plasticization on the lining fabric, producing in this way a uniform adhesive film on the textile surface before it is applied to the canvas. The SEM analysis performed on the sample L_Z682 after dry removal shows in Figure 7C negligible amounts of adhesive residues, while from Figure 7D it may be appreciated that BEVA®371 does not penetrate inside the linen canvas but remains on the surface or else penetrates inside the single yarn.

\section{Conclusions}

In this work the properties of BEVA®371 in the lining operations have been investigated. The results obtained highlighted the different mechanical behaviour between lining with linen or with polyester support. The linen showed highest adhesive strength for the system canvas-adhesive-lining canvas. In particular the higher performance was obtained with the spray application of BEVA®37 compared with spatula and film application, also for different adhesive treatment. Being a thermoplastic adhesive, lining performed with preliminary heating of BEVA®371 on the lining fabric appeared a good solution for minimizing the migration and penetration degree of the adhesive on the painting support, as demonstrated by the marker absorption on cross sections of samples and by the mechanical removal tests of the lining canvas.

SEM observations allowed to visualize that lining removal is not leaving residues on the painting canvas. Therefore future consolidation operations, subsequent to a possible delining will not be significantly limited. 


\section{References}

[1] G.A. Berger, Heat-Seal Lining of a Torn Painting with BEVA®371, Studies in Conservation, 20 (3) (1975) 126-151.

[2] G.A. Berger, W.H. Russel, Conservation of paintings: Research and Innovations, Archetype Pubblications, London 2000. 
[3] J.L. Down, M.A. Macdonald, J. Tetreault, R.S. Williams, Adhesive testing at the Canadian Conservation Institute: An evaluation of selected poly(vinylacetate) and acrylic adhesive. Studies in Conservation 41 (1) (1996) 19-44.

[4] J.L. Down, The evaluation of selected poly(vinyl acetate) and acrylic adhesives: A final research update, Studies in Conservation (2014), in press; http://dx.doi.org/10.1179/2047058414Y.0000000129

[5] C. Young, P. Ackroyd, The mechanical behavior and environmental response of paintings to three types of lining treatments, National Gallery Technical Bulletin 22 (2001) 85-104.

[6] C. Young, R. Hibberd, P. Ackroyd, An investigation into the adhesive bond and transfer of tension in lined canvas paintings, in: Vontobel, R., ed., ICOM Committee 2002.

[7] A. Finozzi, R. Bestetti, F. Rizzi, R. Giorgio, M. Romanò, T. Maifreni, C. Sburlino, M.F. Mecklenburg, C. Lodi, Studio comparato nel comportamento di modelli-finiti sottoposti a diverse trattamenti di impregnazione in condizione di variazioni ambientali, in: L’attenzione alle superfici pittoriche. Materiali e metodi per il consolidamento e metodi scientifici per valutarne l'efficacia -2 . Proceedings of 4 Congresso Internazionale "Colore e Conservazione”, a cura di CESMAR7, Milano, Novembre 21-22, Il Prato Ed., Padova 2008, pp.61-86.

[8] E. Forest, BEVA®371 Film linings: variables affecting bond strength. Master of arts conservation research report, Queen’s University, Kingston, Canada 1997.

[9] E. Knight, Tra non foderatura e uso ragionato degli adesivi da rifodero, in Arte contemporanea, conservazione e restauro. Fiesole, Nardini ed., 1994, pp.157-169. 
[10] K.A. Hardy, The effect of temperature and adhesive thickness on the bond strength of BEVA®371 linings. Master of arts conservation research report, Queen's University, Kingston, Canada 1992.

[11] J. Gayer, The effect of variables on the bond strength of BEVA®371 linings: Further study. Master of arts conservation research report, Queen's University, Kingston, Canada 1992.

[12] D. Daly Hartin, S. Michalski, C. Pacquet, Ongoing research in the CCI lining project: Peel testing of BEVA®371and vax-resin adhesive with different lining supports, in: ICOM Committee for Conservation preprints, 10th Triennial Meeting, Paris. Washington, D.C: ICOM, 1993, pp.128-34.

[13] K. Katz, The quantitative testing and comparisons of peel and lap/shear for Lascaux 360 H.V. and BEVA®371, Journal of the American Institute for Conservation, 24 (2) (1985) 60-68.

[14] J.J. Hawker, The bond strength of two hot table lining adhesive: BEVA®371 and Plextol D360, ICOM Committee for Conservation preprints, 8th Triennial Meeting, Sydney, 1, (1987) 161-168.

[15] P. Ackroyd, A. Phenix, C. Villers, N. Wade, Structural treatments for canvas paintings in 2002: summary of questionnaire replies, in: ICOM committee for conservation, preprints of the 13th Triennial meeting, Rio de Janeiro, September 2227 , James \& James, London, 2002, pp. 321-327.,

[16] M. Rossi Doria, L'uso del BEVA®371 nel consolidamento strutturale di manufatti cartacei. Problemi e soluzioni in: Proceedings of del X Congresso Nazionale IGIIC Lo Stato dell'Arte 10, Roma, November 22-24, 2012, pp.27-34.

[17] G.A. Berger G, Conservation and restoration of pictorial art, N. Brommelle \& P. Smith, , London, UK: Butterworths, 1976, pp. 169- 181. 
[18] C. McGlinchey, R. Ploeger, A. Colombo, R. Simonutti, M. Palmer, O. Chiantore, R. Proctor, B. Lavédrine, E.R. de La Rie, Lining and Consolidating Adhesives: Some New Developments and Areas of Future Research, CCI Symposium on Adhesive and Consolidants for Conservation, 2011.

[19] A. Roche, Approche du principe de réversibilité des doublages des peintures sur toile, Studies in Conservation, 48(2) (2003) 83-94.

[20] A. Phenix, G. Hedley, Lining without heart or moisture, in: Proceedings of the ICOM Committee for Conservation, 7th Triennal Meeting, Copenhagen. (2) (1984) $38-44$.

[21] G. Scicolone, Polimeri a base di PVAc. Confronto di caratterizzazioni chimicofisiche, comportamentali ed estetiche fra 2 polimeri a base di PVAc: Gustav Berger's O.F. 371 e Lascaux 375. Kermes n83, (2011) 63-70.

[22] Gr.Chludzinski, CPC Memo: BEVA®371reformulated in 2010. Available online November 2, 2013 at: www.conservators-products.com/pr01.htm.

[23] ASTM D6862, Standard Test Method for 90 Degree Peel Resistance of Adhesives, (2004).

[24] ASTM D1002, Standard Test Method for Apparent Shear Strength of Single-LapJoint Adhesively Bonded Metal Specimens by Tension Loading (Metal-to-Metal), (2004).

[25] R. Ploeger, E. René de la Rie, C.W. McGlinchey, M. Palmer, C.A. Maines, O. Chiantore, The long-term stability of a popular heat-seal adhesive for the conservation of painted cultural objects, Polymer Degradation and Stability, http://dx.doi.org/10.1016/j.polymdegradstab.2014.01.031, in press. 


\section{Captions to figures}

Fig. 1. Scheme of the adhesion tests : peeling (A) and lap shear (B).

Fig. 2. Peel test results: the blue curves are for the BEVA applied in spray and lining at $68^{\circ} \mathrm{C}$; the orange curves are for the BEVA applied in spray with re-plasticization and lining at $68^{\circ} \mathrm{C}$. On the left the results before the ageing, on the right the results after the ageing.

Fig. 3. Lap shear test results: on the left comparison between L_Z682 and P_Z682 series; on the right comparison between P_S621 and P_Z621 series. Curves with dark color and "IN" suffix refer to data after ageing of samples.

Fig. 4. Fluorescence images of cross-sections after treatment with BEVA 371 by spraying on the linen canvas: (A) direct lining at $68^{\circ} \mathrm{C}$ (sample L_Z681); (B) BEVA pre-heated at $68^{\circ} \mathrm{C}$ before lining (sample L_Z682). 1: preparatory layer, 2: painting canvas, 3: BEVA, 4: lining fabric.

Fig. 5. Removal test of canvas de-lining on samples P_F68. The four stereomicroscope images show the area of separation between the painting canvas (upper part) and the lining fabric (lower part): (A) dry mechanical removal; (B) solvent removal with cyclohexane; (C) hot removal with air gun at $36^{\circ} \mathrm{C}$; (D) hot removal wih IR lamp at 50 ${ }^{\circ} \mathrm{C}$.

Fig. 6. Stereomicroscope images acquired after the dry mechanical removal of de-lining canvas for samples L_F68 (A) and L_F75 (B). In the image (B) it is seen that the BEVA Film re-plasticization at higher temperatures is less reversible.

Fig. 7.Top: stereomicroscope images of dry removal between painting canvas (on the right of image) and the lining fabric (on the left). (A) sample L_Z681; (B) sample L_Z682 .

Down: SEM images of L_Z682 sample. (C): painting support after lining canvas removal (69x); (D) higher magnification (300x) of a BEVA scrap on the surface of textile fibres. 
Click here to download high resolution image
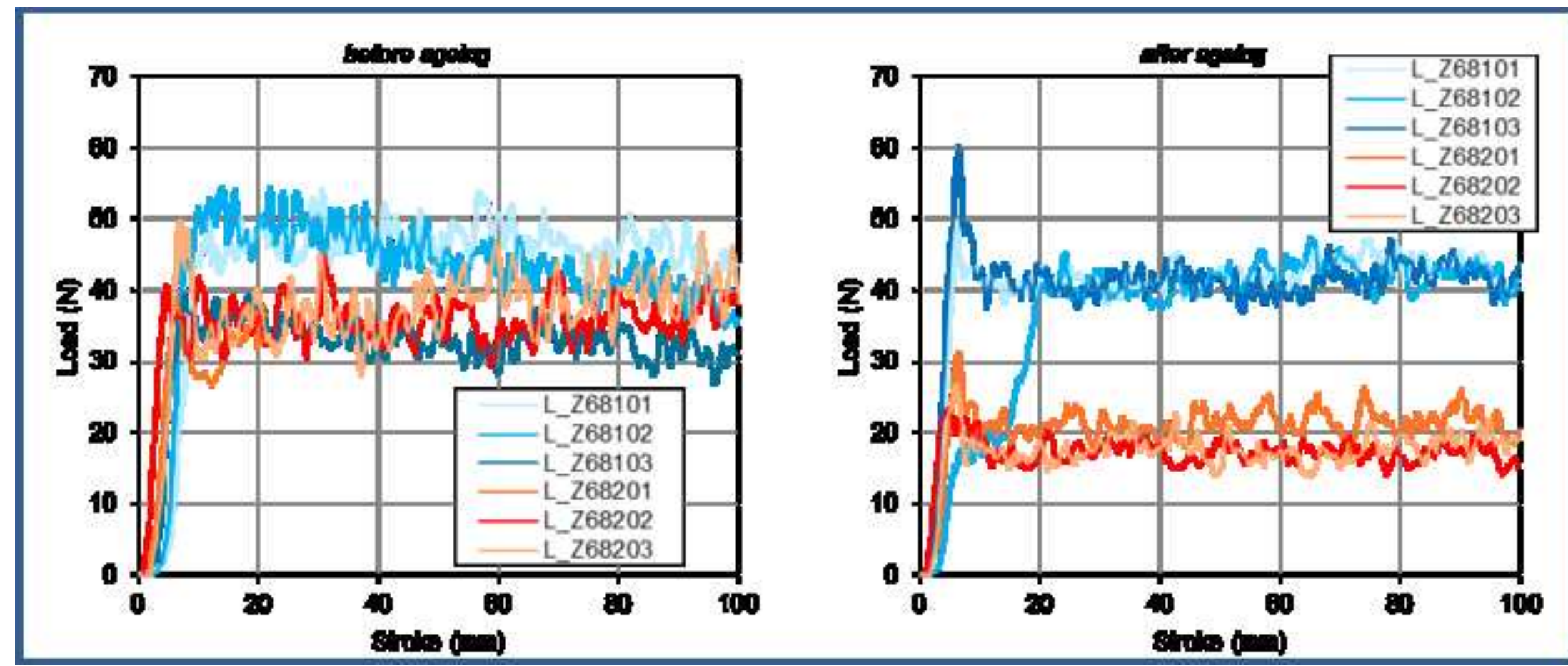

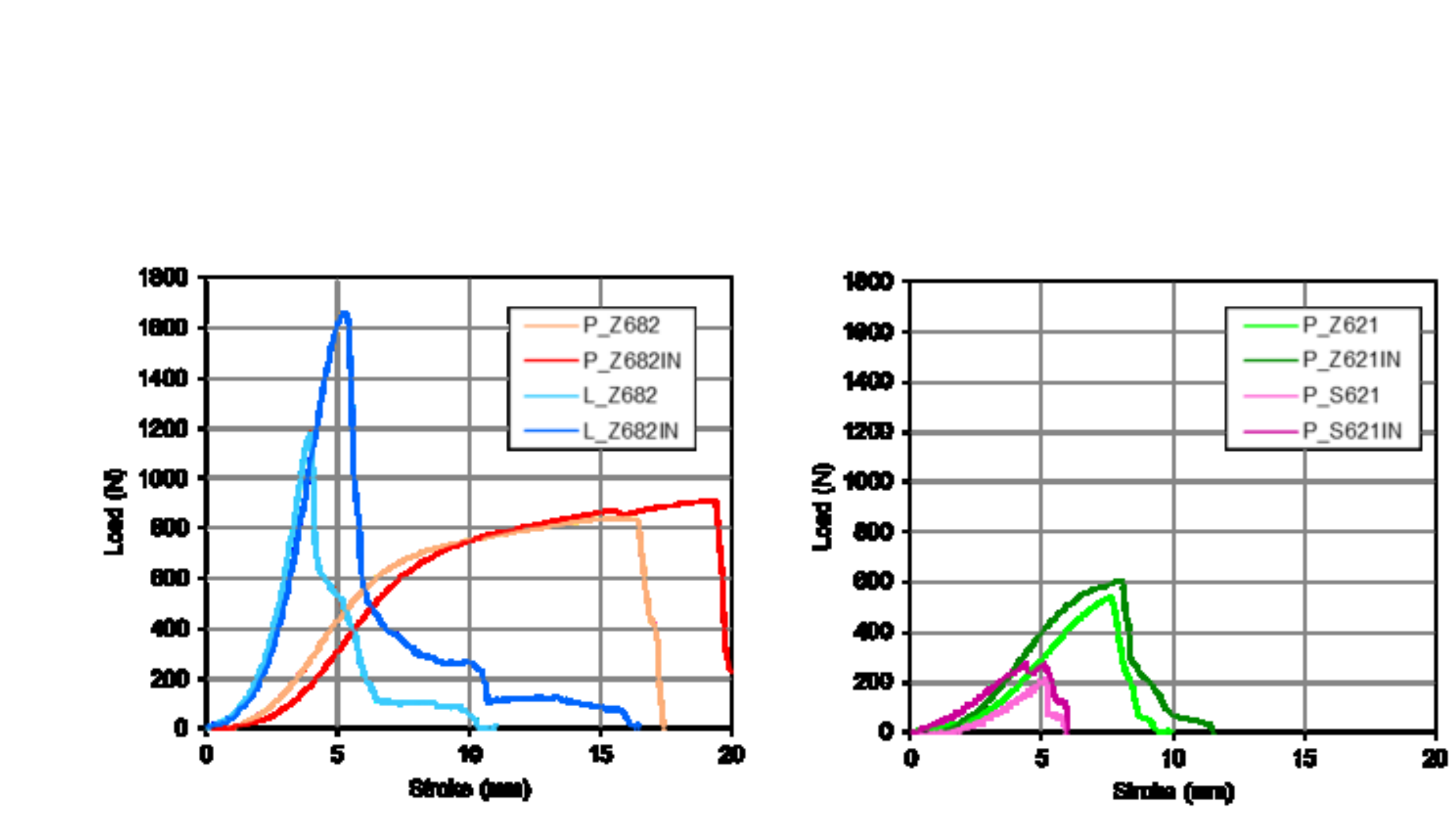

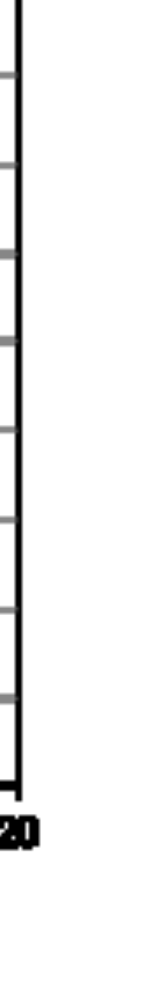

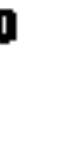




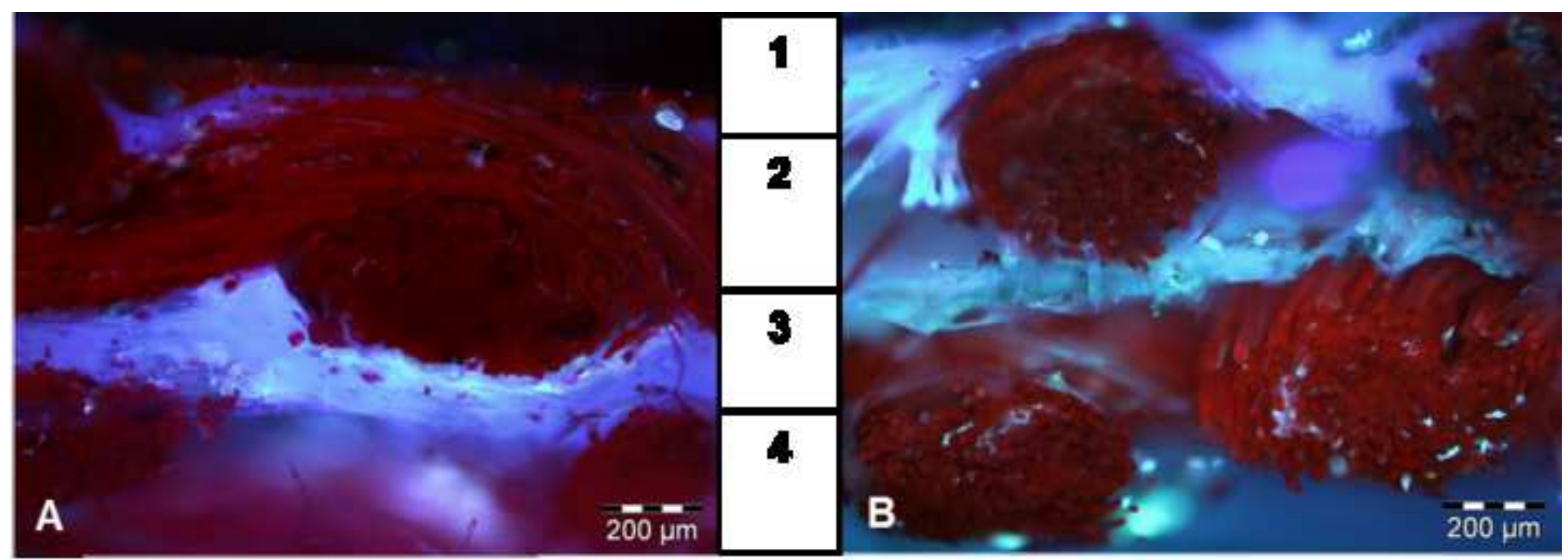



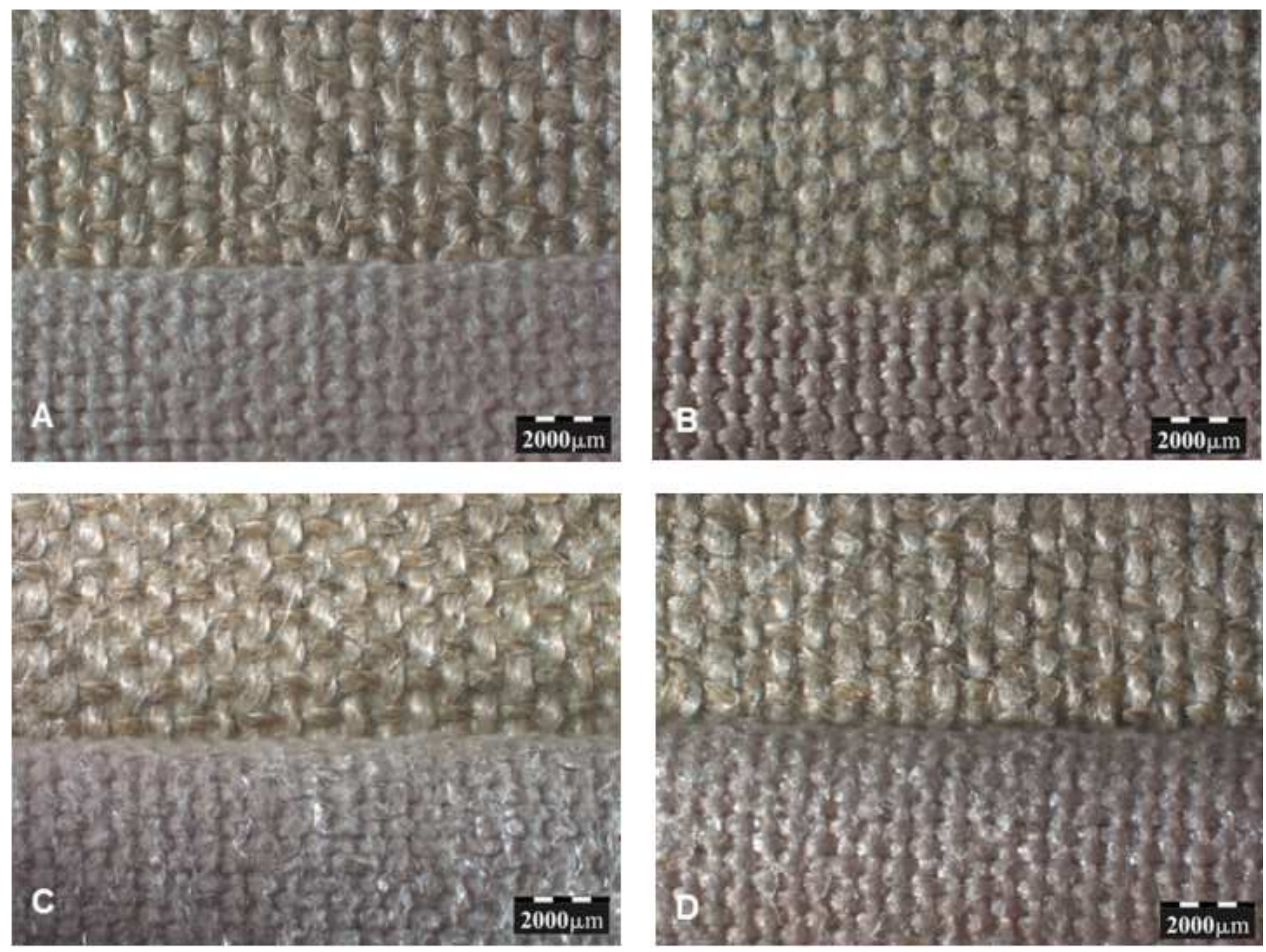
Click here to download high resolution image
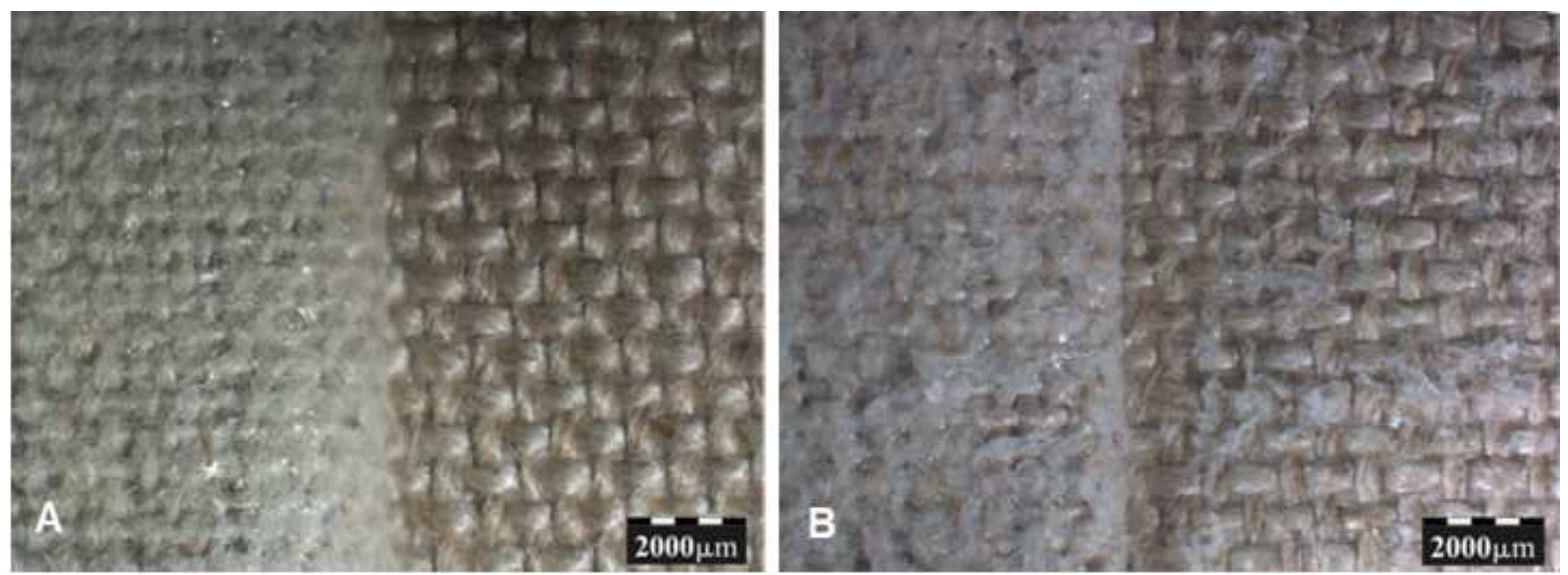
Click here to download high resolution image
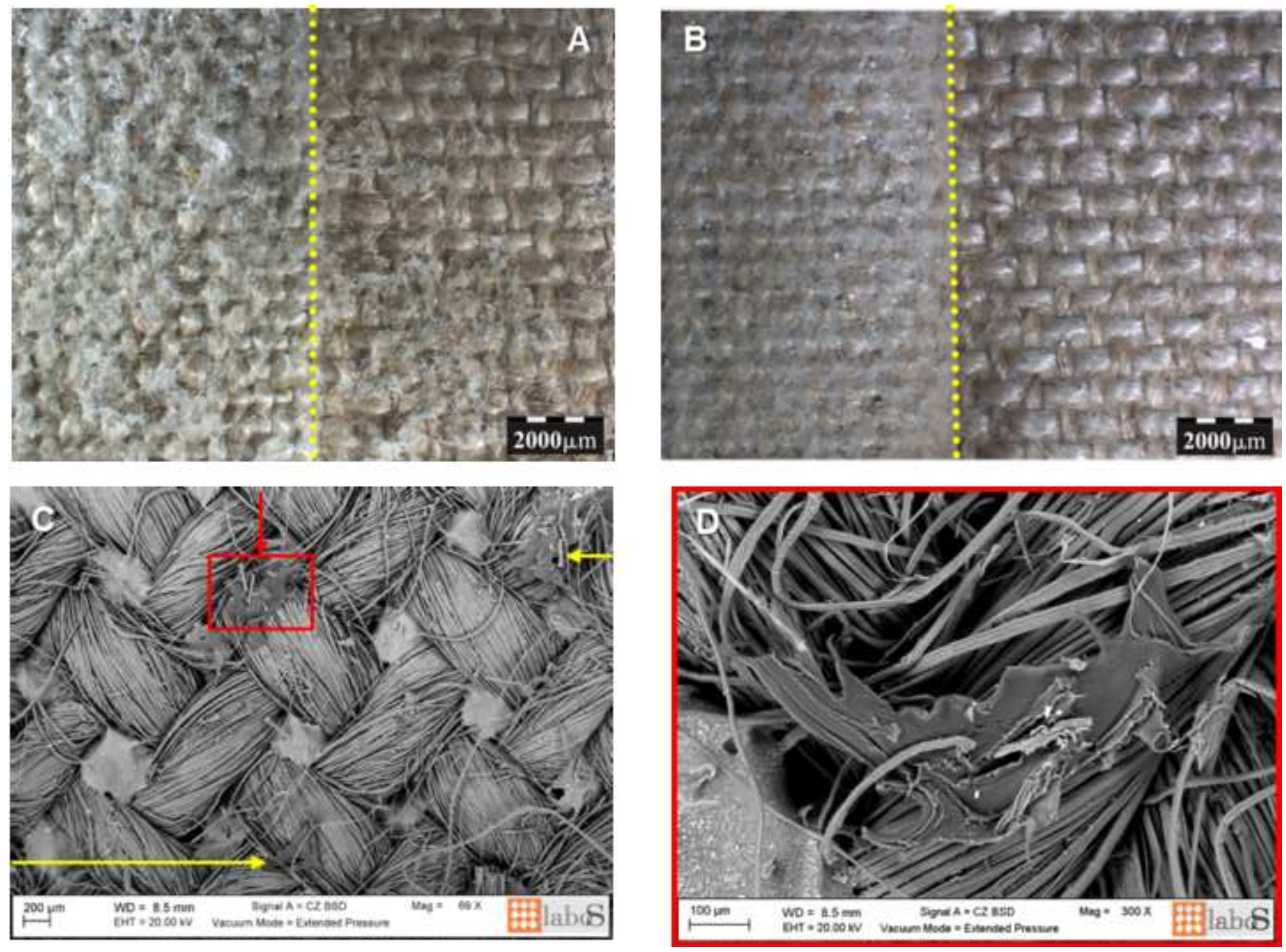


\section{Table 1}

Specimen series examined in the work. The nomenclature, in the form L_F621 stands for L (or P) support type (linen or polyester), $\mathrm{F}$ (or S or Z) application method (film or spatula or spray), $62{ }^{\circ} \mathrm{C}$ (or $68^{\circ} \mathrm{C}$ or $75^{\circ} \mathrm{C}$ ) re-plasticization temperature, 1 (or 2) different lining procedures (lining performed at the selected temperature or the adhesive was heated on the auxiliary fabric before lining with low pressure and temperature).

\begin{tabular}{|l|l|}
\hline \multicolumn{2}{|c|}{ TYPE } \\
\hline L SERIES & P SERIES \\
\hline L_F62 & P_F62 \\
\hline L_F68 & P_F68 \\
\hline L_F75 & P_F75 \\
\hline L_S621 & P_S621 \\
\hline L_S622 & P_S622 \\
\hline L_S681 & P_S681 \\
\hline L_S682 & P_S682 \\
\hline L_Z621 & P_Z621 \\
\hline L_Z622 & P_Z622 \\
\hline L_Z681 & P_Z681 \\
\hline L_Z682 & P_Z682 \\
\hline
\end{tabular}


Table 2

Peel test results.

\begin{tabular}{|l|c|l|c|}
\hline \multicolumn{1}{|c|}{ L series } & $\begin{array}{c}\text { Peel strength } \\
(\mathrm{N} / \mathrm{m})\end{array}$ & \multicolumn{1}{|c|}{ P series } & $\begin{array}{c}\text { Peel strength } \\
(\mathrm{N} / \mathrm{m})\end{array}$ \\
\hline L_F62 & $10 \pm 2$ & P_F62 & $1 \pm 1$ \\
\hline L_F68 & $50 \pm 3$ & P_F68 & $20 \pm 1$ \\
\hline L_F75 & $350 \pm 30$ & P_F75 & $240 \pm 40$ \\
\hline L_S621 & $300 \pm 10$ & P_S621 & $30 \pm 10$ \\
\hline L_S622 & $20 \pm 10$ & P_S622 & $20 \pm 10$ \\
\hline L_S681 & $100 \pm 10$ & P_S681 & $40 \pm 10$ \\
\hline L_S682 & $100 \pm 10$ & P_S682 & $30 \pm 4$ \\
\hline L_Z621 & $250 \pm 20$ & P_Z621 & $50 \pm 4$ \\
\hline L_Z622 & $100 \pm 10$ & P_Z622 & $20 \pm 3$ \\
\hline L_Z681 & $380 \pm 10$ & P_Z681 & $200 \pm 20$ \\
\hline L_Z682 & $350 \pm 10$ & P_Z682 & $100 \pm 10$ \\
\hline
\end{tabular}


Table 3

Lap shear test results. The "IN" suffix refer to after ageing tests.

\begin{tabular}{|c|c|c|c|}
\hline L series & $\begin{array}{c}\text { Detach load } \\
\left(\mathrm{N} / \mathrm{mm}^{2}\right)\end{array}$ & P series & $\begin{array}{c}\text { Detach load } \\
\left(\mathrm{N} / \mathrm{mm}^{2}\right)\end{array}$ \\
\hline L_F68 & 0.190 & P_F68 & 0.100 \\
\hline L_F68 IN & 0.280 & P_F68 IN & 0.116 \\
\hline L_S681 & 0.290 & P_S621 & 0.044 \\
\hline L_Z621 & 0.070 & P_S621 IN & 0.055 \\
\hline L_Z622 IN & 0.230 & P_Z621 & 0.110 \\
\hline L_Z682 & 0.240 & P_Z621 IN & 0.120 \\
\hline L_Z682 IN & 0.330 & P_Z622 & 0.075 \\
\hline \multicolumn{3}{|c|}{ P_Z622 IN } & 0.100 \\
\hline P_Z682 & 0.170 \\
\hline \multicolumn{3}{|c|}{ P_Z682 IN } & 0.180 \\
\hline
\end{tabular}


Table 4

Peel strength before and after ageing.

\begin{tabular}{|c|c|c|}
\hline & \multicolumn{2}{|c|}{ Peel strength (N/m) } \\
\hline Series/Sample & Before ageing & After ageing \\
\hline L_F62 & 30 & 10 \\
\hline L_F68 & 100 & 50 \\
\hline & & \\
\hline L_S621 & 50 & 30 \\
\hline L_S622 & 40 & 20 \\
\hline L_S681 & 100 & 100 \\
\hline L_S682 & 100 & 100 \\
\hline & & \\
\hline L_Z621 & 160 & 250 \\
\hline L_Z622 & 50 & 100 \\
\hline L_Z681 & 400 & 390 \\
\hline L_Z682 & 200 & 350 \\
\hline & & \\
\hline P_F62 & 13 & 1 \\
\hline P_F68 & 50 & 20 \\
\hline & & \\
\hline P_S621 & 10 & 30 \\
\hline P_S622 & 1 & 20 \\
\hline P_S681 & 70 & 40 \\
\hline P_S682 & 40 & 40 \\
\hline & & 50 \\
\hline P_Z621 & 40 & 100 \\
\hline P_Z622 & 30 & \\
\hline P_Z681 & 200 & \\
\hline P_Z682 & 100 & \\
\hline & & \\
\hline & & \\
\hline & & \\
\hline & & \\
\hline & & \\
\hline & & \\
\hline & & \\
\hline & & \\
\hline & & \\
\hline & & \\
\hline & & \\
\hline & & \\
\hline & & \\
\hline & & \\
\hline & & \\
\hline
\end{tabular}




\title{
Detailed Response to Reviewers
}

\author{
Università degli Studi di Torino \\ Dipartimento di Chimica \\ Via P. Giuria, 710125 Torino Italy

\section{Response to the referee's comments of the manuscript "USE AND REVERSIBILITY OF BEVA ${ }^{\circledR 371}$ ON THE LINING OF PAINTINGS" (CULHER-D-13-00293)}

\section{Ref\#1}

- Text revised, following the reviewer's suggestions.

- Experimental details have been added, as requested.

\section{Ref\#2}

- Pag 2, line 43: A ref may be 20 years old, but still valid in the particular field of interest. Ref (3) is still now the most exhaustive scientific evaluation of adhesives and consolidants used in conservation. The results there reported are confirmed by the incoming publication of the same Author (Jane Down) soon to appear in Studies in Conservation, which we have now added as reference.

- Pag 4, line 38: paragraph rewritten: the sentence here commented is canceled.

- Pag. 5, line 30: information added.

- Pag. 6, line 29: complete solvent evaporation was assumed, but not experimentally determined. The sentence has been changed into a more appropriate form.

- Pag 9, line 9: the sentence "the effects produced by different -canvas -adhesive -lining interfaces" means exactly what the referee is saying in relation to the difficulty of testing composite materials where the adhesive layers might be not homogeneous, etc.

- Pag.10, line 56; pag. 11, line 32; pag. 11, line 43: it is criticized the fact that "nothing has been said about the cohesive properties of linings". It is true, because aim of the study was to test the reversibility of BEVA in lining operations, considered from conservator's perspective. We are not reporting the "real mechanical effectiveness of Beva linings", but using the measurements of adhesive strength in the different application modes / materials for finding correlations with aging and removal.

- Pag. 11, line 47 an line 56: The paragraph has been rewritten to express more clearly the conclusion.

\section{Ref. \#3}

- Pag 6 line 55 - : requested details have been added.

- Pag 8: Response to the comment:

show force -displacement graph for one or more of your tests. Rewrite stationary as "steadystate" if indeed that was achieved need to show graph to show a steady state of peel was achieved.

Not sure what stroke is referring to?

The reference to Figure 2, where some results of the peel tests, in terms of forcedisplacement curve, has been added in the text. The word stationary has been substituted as suggested. The stroke is the vertical displacement of the mobile part of the testing machine, where one end of the specimen is fixed.

- Response to the comment: 


\section{Università degli Studi di Torino \\ Dipartimento di Chimica}

Via P. Giuria, 710125 Torino Italy

This test is for bonded metals not flexible canvas. The shear lap even with additional strength at the grips will go into bend. Please discuss the results and show the graphs that justify the use of this test to evaluate the bond. "tearing "?!! strength -this test measures the shear strength of the adhesive.

Lap shear tests are a typical way to evaluate the strength of adhesives in the most likely loading mode for adhesives, and a standard tool for comparison of most adhesives. Some bending of the adherends is unavoidable with any material including metals, and this justifies tests more complex than the simplest single-lap shear. In any case, these tests are more qualitative than quantitative and are intended to be used for comparison between different treatments (in this case) or different materials, adhesives, etc. in other cases. Therefore, we consider these additional results as good indicators and sources of valuable information about the quality of the analyzed processes and treatments.

\section{- Pag. 8: Visualization of Beva penetration}

The dye applied on the cross-sections allows the observation of Beva penetration because it can penetrate only where the adhesive is not present.

- Pag 9: Requested details have been added about lining removal and microscope observation of efficacy.

- Pag 10:

Response to the comment:

graph show a reduction in gradient of the load displacement indicates decreased stiffness, type of failure indicated more brittle behavior. But this shear test is not very valid as it is actually mixed mode shear and bend and therefore hard to intepret.

Also one set of data appear to be at 68 degrees and the other at 62 degrees. Write in the critical region for BEVA s ot he effect might just be temp not age.

We agree with the comment, the statement in the text was not completely clear and, indeed, it can bring to misunderstanding. The sentence has been now modified. The maximum load of the curves is always higher for the specimen after the ageing, so it seems that the ageing increases the shear strength. In agreement with the comments of the referee, it seems also that the temperature increase this phenomenon. As discussed also in a comment above, some bending of the adherends is unavoidable and the stress is not purely shear. However this test is widely used for this type of measure. This test is more qualitative than quantitative and is used, also in this case, to compare different treatment.

- $\quad$ Section 3.2

Comment to Figures 4 and 5:

the images (especially 4) need annotating it is not clear which is the lining and which is the canvas. The BEVA appears to be on both sides of one of the fabrics in B. please describe what features you which to point out to aid the reader.

Figure 5 needs figure titles. and more description in the text.

A more detailed description of the figure has been added in the text and in the captions. 